\title{
Joining of alumina by using organometallic polymer
}

\author{
Ken'ichiro KITA, ${ }^{\dagger}$ Naoki KONDO, Yasuhisa IZUTSU* ${ }^{*}$ and Hideki KITA \\ National Institute of Advanced Industrial Science and Technology (AIST), 2266-98 Shimo-shidami, Moriyama-ku, Nagoya 463-8560 \\ *Stereo Fabric Research Association, 2266 Shimo-shidami, Moriyama-ku, Nagoya 463-8560
}

\begin{abstract}
This paper describes a novel experiment involving the joining of alumina using polycarbosilane (PCS). PCS filled in the cracks on the surface of alumina, the silicon in PCS oxidized to silicon dioxide $\left(\mathrm{SiO}_{2}\right)$, and part of $\mathrm{SiO}_{2}$ reacted with alumina to form mullite during pyrolysis of $\mathrm{PCS}$ at 1673 and $1873 \mathrm{~K}$. The $\mathrm{SiO}_{2}$ and mullite acted as a binder between the alumina boards. 4-point bending tests showed the average flexural strength of the samples pyrolyzed at $1673 \mathrm{~K}$ was $81.8 \mathrm{MPa}$, whereas that of the samples that pyrolyzed at $1873 \mathrm{~K}$ was $109 \mathrm{MPa}$. The difference in flexural strength was caused by the difference in the thickness and the compounds of the joining area, which was brought by the diffusion of the decomposition products derived from PCS and alumina during pyrolysis.
\end{abstract}

(C2011 The Ceramic Society of Japan. All rights reserved.

Key-words : Polycarbosilane, Mullite, Alumina, Joining

[Received April 12, 2011; Accepted May 18, 2011]

\section{Introduction}

Ceramic materials generally have good thermal stability and corrosion resistance because of their composition, which consists of covalent or ionic bonds. Therefore, ceramics show a potential for use in many fields, especially those that involve high-energy operations. ${ }^{1), 2)}$ However, the production of large sized ceramics is very difficult and expensive, because the process requires the use of huge furnaces and large amounts of energy. Therefore, joining is currently considered one of the best methods of producing such ceramics.

The joining of ceramics, however, is very difficult because of their own thermal stability and corrosion resistance. Especially, it is well known that the joining of alumina is particularly difficult because the bond energy is extremely high. Based on these facts, possible methods for joining alumina have been investigated, and several methods have been proposed. ${ }^{3)-6 \text { ) }}$

For example, one of the methods involves joining alumina using metals such as copper. Metal oxide or metal sulfide with additives are used as the binder of alumina, and these are heated to temperatures greater than $1273 \mathrm{~K}$. Joining at low temperatures, less than $1000 \mathrm{~K}$, can be carried out when $\mathrm{PbO}$ is used as a binder, however, the use of $\mathrm{Pb}$ is problematic. This method is very useful because it does not require grinding of the alumina surface before joining or use of any specific machining for joining. However, with this method, metals easily remain in the joined alumina and weaken the joined alumina during heating. ${ }^{7)}$ Moreover, PVD can be another candidate to join alumina, although it has limitations with respect to the size and the cost of the joined alumina. ${ }^{8)}$

Considering the thermal resistance after joining and the cost, the method of soldering using an oxide solder is suitable for large-scale ceramic production. With this method, no metal remains in the joined alumina, and the flexural strength of the joined alumina is maintained. However, such solders consist of several kinds of inorganic oxides and elements in these oxides

Correspondence author: K. Kita; E-mail: kita.kennichiro@aist. go.jp remain in the joined alumina, and there is some possibility that the remaining elements become impurities, which may damage the joined alumina or the commodity produced using the joined alumina. Therefore, the use of excess elements, which are dissimilar to aluminum, should be avoided or minimized in joining.

To devise a method to join alumina, we discuss the role of organometallic polymers of a ceramic precursor. These organometallic polymers usually consist of single light or semi metals, and some nonmetals such as hydrogen, boron, carbon, nitrogen, and oxygen. ${ }^{9}$ These polymers can be made into ceramics through heating at $1273 \mathrm{~K}$, and the decomposition of these polymers can cause their diffusion into the adjoining ceramics. It is expected that the diffusion of the decomposition products brings about the anchor effect, which enables alumina to join another ceramic easily and firmly.

In this study, we focused our attention on polycarbosilane (PCS). This well-known polymer is the precursor of silicon carbide $(\mathrm{SiC}) .{ }^{10)}$ There have been many reports on the binders for bulk $\mathrm{SiC}$ and fiber-reinforced plastics with SiC-based fibers, and some methods described in these reports have been applied. ${ }^{11)-14)}$ PCS easily reacts with oxygen because of the formation of the $\mathrm{Si}-\mathrm{H}$ group upon heating. ${ }^{15}$ ) Therefore, it is expected that the surface of alumina covered by molten PCS becomes active during heating and that this activity enables the alumina to be joined to another ceramic easily. Additionally, PCS can be made into $\mathrm{SiC}$ and $\mathrm{SiO}_{2}$, and it is expected that the surface of alumina can be made into mullite as the middle layer of the joining.

From the above properties of PCS, it is expected that PCS can become a binder for joining oxide ceramics. However, thus far, there has been little study of PCS with regard to its potential application as a binder for oxide ceramics. Our investigation thus focuses on this important potential application of PCS.

\section{Experimental procedure}

The outline of the experimental procedure is shown in Fig. 1. Alumina plates $\left(400 \mathrm{~mm}^{2}\right.$ square and $4 \mathrm{~mm}$ thickness) were cut out from bulk alumina, which was more than $99.9 \%$ pure, and with an average grain size of approximately $2 \mu \mathrm{m}$ (Mitsui 

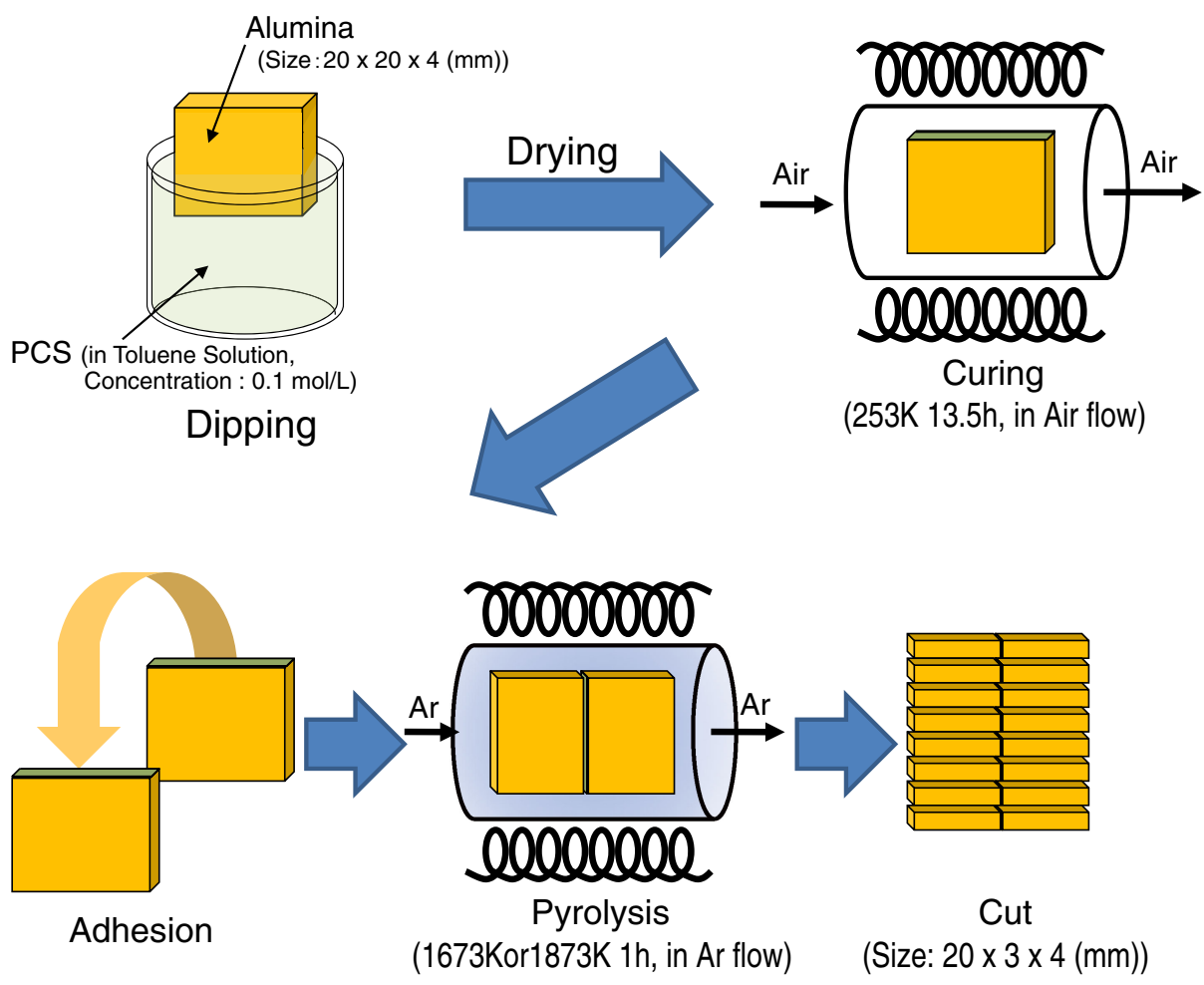

Fig. 1. (Color online) Outline of this experiment.

Kinzoku Corporation). One of the surfaces of the alumina plates, measuring $80 \mathrm{~mm}^{2}$ and unground, was prepared. Hereafter, the alumina plates are referred to as "boards" and the following investigations were carried out on the ground surface.

The PCS (NIPUSI Type-A, NIPPON CARBON, Japan) used in this experimental procedure was dissolved into dehydrated toluene to a concentration of $0.1 \mathrm{~mol} / \mathrm{L}$. The boards were dipped into the toluene solution and dried using an air blower; after drying, the boards were cured at $253 \mathrm{~K}$ under air flow for $13.5 \mathrm{~h}$. After a few repetitions of dipping and curing, two of the boards were chosen, and the ground surfaces of the chosen boards were adhered. The adhered board was pyrolyzed at 1673 or $1873 \mathrm{~K}$ for $1 \mathrm{~h}$ under air.

Following pyrolysis, the pyrolyzed board was cut into stickshaped samples for the flexure test (the size of the stick is shown in Fig. 1). The joining area of the pyrolyzed board was observed by scanning electronic microscopy (SEM; JEM-5600, JEOL, Japan) and energy dispersive X-ray spectroscopy (EDS; JEM5600, JEOL, Japan). After these observations, the 4-point bending test was carried out to investigate the flexural strength of these samples.

Besides, alumina powder covered by PCS was prepared, cured, and pyrolyzed at the same conditions as the above to investigate the reaction of alumina and PCS in pyrolysis. The pyrolyzed powder was investigated by X-ray diffraction (XRD; RINT2500, Hitachi Ltd., Japan).

\section{Results and discussion}

Figure 2 shows the SEM image and EDS maps of the cross section of the joining area after pyrolysis at $1673 \mathrm{~K}$. The joining area is the white gray area in the center of the SEM image, and the alumina plates are the deep gray areas on both sides of the joining area. The image indicates that there was no crack between the joining area and alumina, and it reveals that PCS completely permeated the cracks on the surface of the alumina plates. The width of the joining area was approximately $15 \mu \mathrm{m}$. The distribution of silicon, aluminum, and oxygen in the area was observed by EDS. The silicon peak, which could be barely observed in the alumina plates, was clearly observed in the joining area. Conversely, the peak of aluminum, which was very strong in the alumina plates, was scarcely observed in the joining area. As for the peak of oxygen, there was no remarkable difference in the observed peaks between the aluminum plates and joining area.

Figure 3 shows the SEM image and EDS maps of the cross section of the joining area after pyrolysis at $1873 \mathrm{~K}$. The joining area of the sample is in the center of the image and there are boundaries, which could be seen between the joining area and alumina plates. No cracks are seen between the joining area and alumina plates and this suggests that the joining area was slightly depressed. The width of the joining area was about $5 \mu \mathrm{m}$. The EDS maps of silicon, aluminum, and oxygen were also observed. In the joining area the silicon peak was strong and that of aluminum weak, whereas that of silicon decreased and that of alumina increases in the alumina plate. Besides, a silicon rich area existed in the alumina plate (see the area over the scale bar in Fig. 3). It is considered that a part of the joining area diffused and the diffusion made the joining area thinner than the joining area of the sample pyrolyzed at $1673 \mathrm{~K}$.

Table 1 shows the EDS quantitative analysis results for the joining area in the samples pyrolyzed at 1673 and $1873 \mathrm{~K}$. EDS shows the counts of each element and the counts are regarded as units for convenience. Moreover, to show any clear differences methodically, the average composition of 10 points on the joining areas is shown in Table 1. In the case of the joining area of the sample pyrolyzed at $1673 \mathrm{~K}$, the area consisted of 14.4 mass $\%$ of aluminum, 37.7 mass $\%$ of silicon, 41.3 mass $\%$ of oxygen, and 6.6 mass $\%$ of other elements. As for that pyrolyzed 


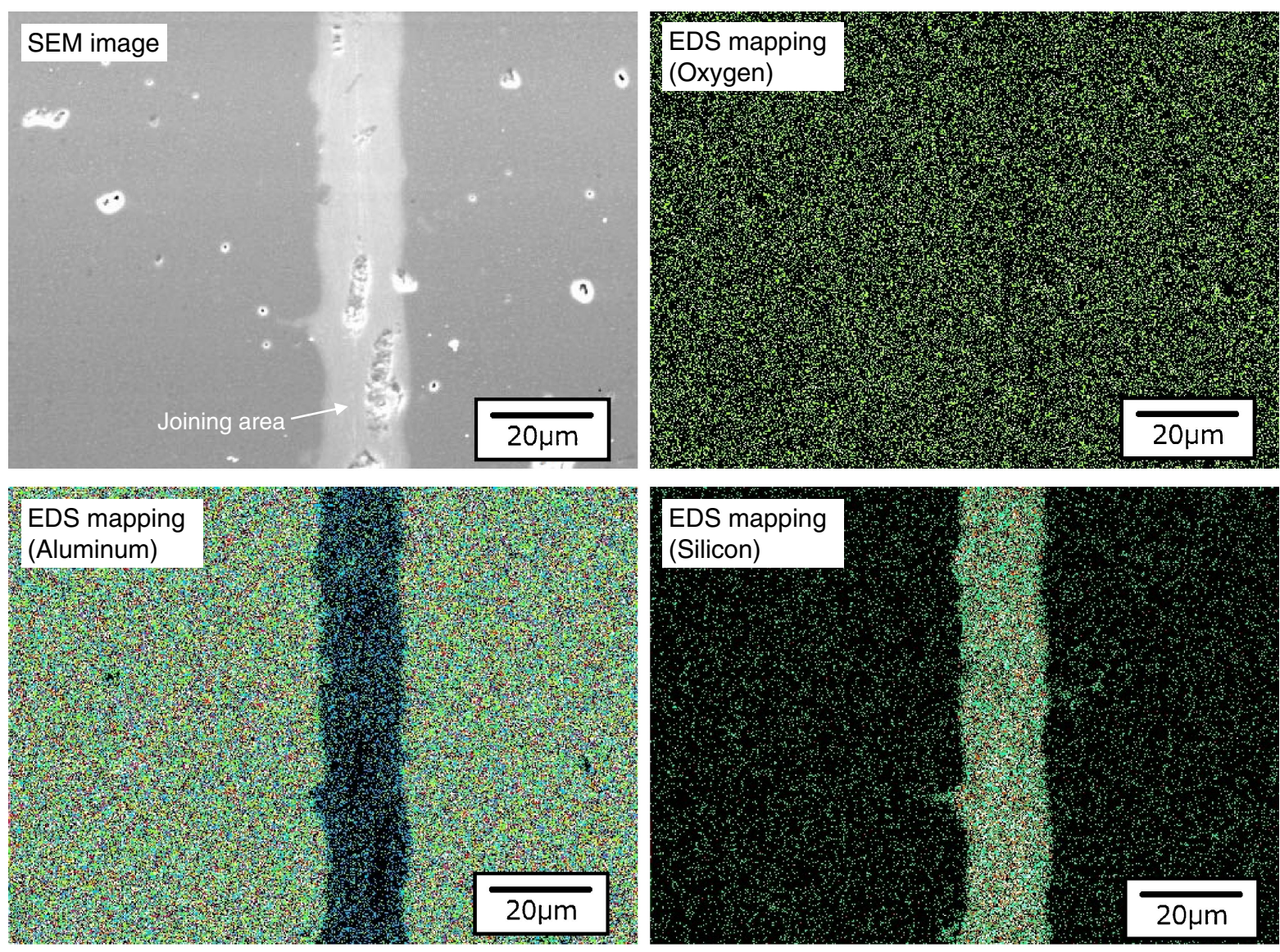

Fig. 2. (Color online) SEM image and EDS mappings of the cross section of the joining area after pyrolysis at $1673 \mathrm{~K}$.

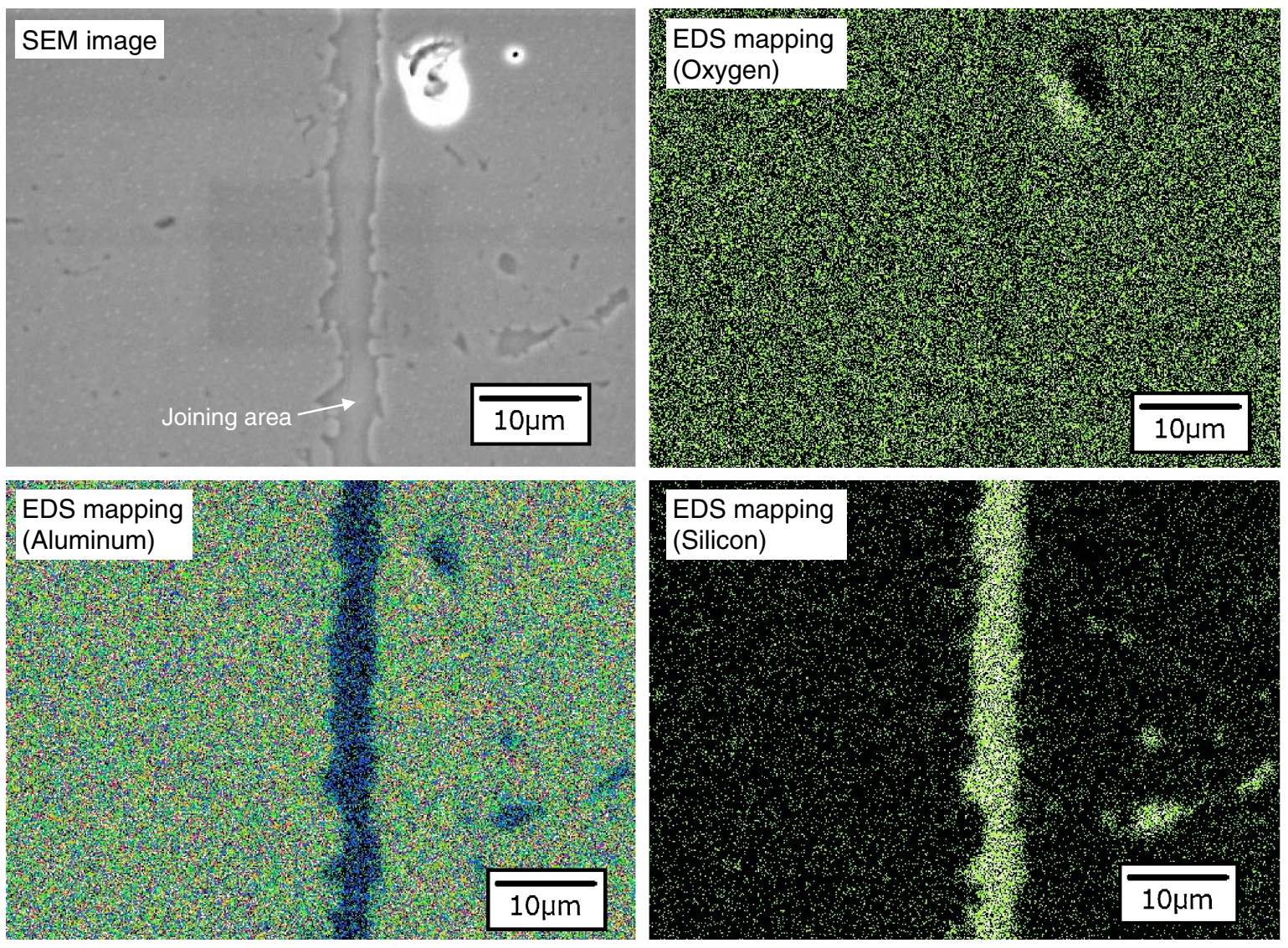

Fig. 3. (Color online) SEM image and EDS mappings of the cross section of the joining area after pyrolysis at $1873 \mathrm{~K}$. 


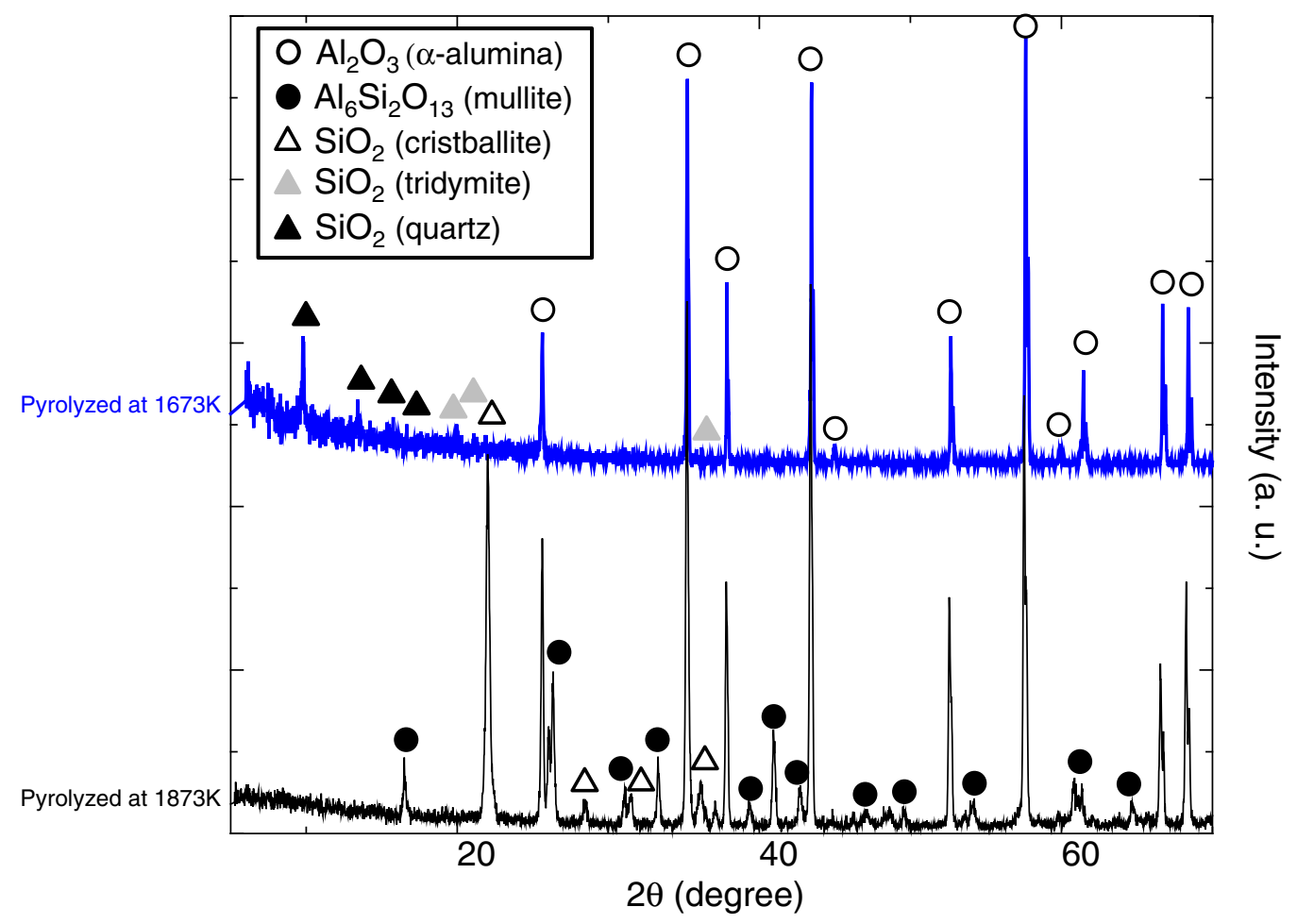

Fig. 4. (Color online) XRD pattern of the joining area of thesamples pyrolyzed at 1673 and $1873 \mathrm{~K}$.

Table 1. Quantitative analysis for the joiningarea in the samples pyrolyzed at 1673 and $1873 \mathrm{~K}$ by EDS

\begin{tabular}{lcc}
\hline Elements & $\begin{array}{c}\text { Joining area of the } \\
\text { sample pyrolyzed } \\
\text { at } 1673 \mathrm{~K}\end{array}$ & $\begin{array}{c}\text { Oining area of the } \\
\text { sample pyrolyzed } \\
\text { at } 1873 \mathrm{~K}\end{array}$ \\
\hline Aluminum & 14.4 & 18.6 \\
Silicon & 37.7 & 36.3 \\
$\begin{array}{l}\text { Oxygen } \\
\text { Others } \\
\text { (Sodium, Magnesium, etc.) }\end{array}$ & 41.3 & 39.0 \\
\hline
\end{tabular}

at $1873 \mathrm{~K}$, the area consisted of 18.6 mass $\%$ of aluminum, 36.3 mass $\%$ of silicon, 39.0 mass $\%$ of oxygen, and 6.1 mass $\%$ of other elements. Aluminum was mainly derived from alumina; therefore, it reveals that the diffusion of alumina into the joining area increased at $1873 \mathrm{~K}$ relative to that at $1673 \mathrm{~K}$. This agrees with the observation that the joining area was thinner than that pyrolyzed at $1673 \mathrm{~K}$.

To investigate the reaction of alumina and PCS during pyrolysis, the alumina powder was covered with PCS; the powder was cured and pyrolyzed at the same conditions as the above. Figure 4 shows the XRD pattern of the pyrolyzed powders. In the case of the powder pyrolyzed at $1673 \mathrm{~K}$, most peaks indicate alumina and two peaks at 20.4 and $21.8^{\circ}$ suggest tridymite, and some peaks at less than $20^{\circ}$ such as 9.78 and $13.4^{\circ}$ suggest quartz. As for the powder pyrolyzed at $1873 \mathrm{~K}$, the peaks, which suggest the existence of mullite $\left(\mathrm{Al}_{6} \mathrm{Si}_{2} \mathrm{O}_{13}\right)$, such as $16.5,26.4,31.1^{\circ}$, etc. were clearly observed. The cristobalite peaks at 22.0 and $28.4^{\circ}$ were also observed. From the above results, it is thought that the joining area of the sample pyrolyzed at $1673 \mathrm{~K}$ consisted of tridymite and quartz, and that of the sample pyrolyzed $1873 \mathrm{~K}$ consisted of mullite and cristobalite.

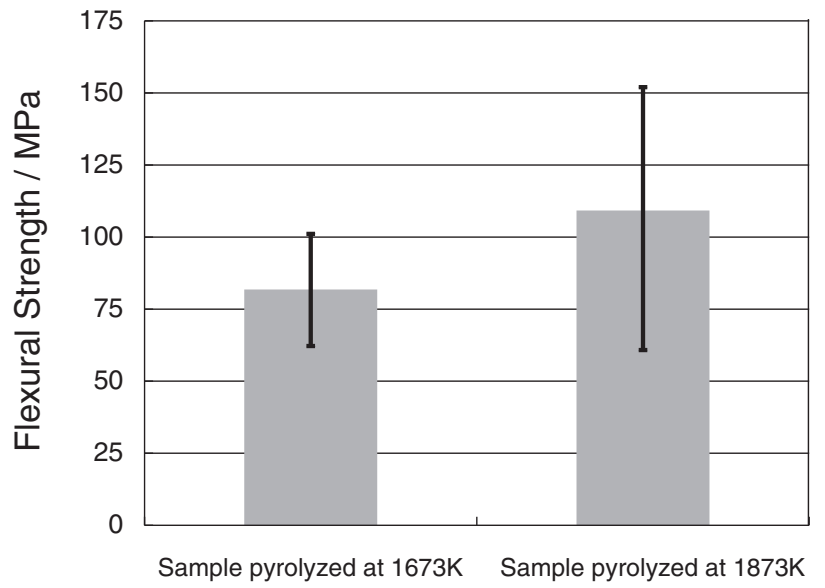

Fig. 5. Flexural strengths of the 4 point bending tests of the samples.

Figure 5 shows the average flexural strengths of the 4-point bending tests of the samples pyrolyzed at 1673 and $1873 \mathrm{~K}$, and the detailed test results are listed in Table 2. In the tests, 6 samples were fired at $1673 \mathrm{~K}$ and 10 samples at $1873 \mathrm{~K}$, and subsequently, their flexural strengths were investigated. The $y$-axis of the graph in Fig. 5 shows the value of the flexural strength. The average strength of the samples pyrolyzed at $1673 \mathrm{~K}$ was $81.8 \mathrm{MPa}$ and the maximum was $101 \mathrm{MPa}$. The average strength of the samples pyrolyzed at $1873 \mathrm{~K}$ was $109 \mathrm{MPa}$ and the maximum was $152 \mathrm{MPa}$. It is assumed that the flexural strength of the samples pyrolyzed at $1873 \mathrm{~K}$, which was higher than that of the samples pyrolyzed at $1673 \mathrm{~K}$, was driven by diffusion that forms the narrow joining area and generates mullite.

Figure 6 shows the Weibull distribution of the 4-point bending tests of the samples pyrolyzed at 1673 and $1873 \mathrm{~K}$. 
Table 2. 4 point bending tests

\begin{tabular}{lcc} 
& & (Unit: MPa) \\
\hline Temperature in Pyrolysis & $1673 \mathrm{~K}$ & $1873 \mathrm{~K}$ \\
\hline Number & 6 & 10 \\
Average & 81.8 & 109 \\
Maximum & 101 & 152 \\
Minimum & 62.2 & 60.8 \\
\hline
\end{tabular}

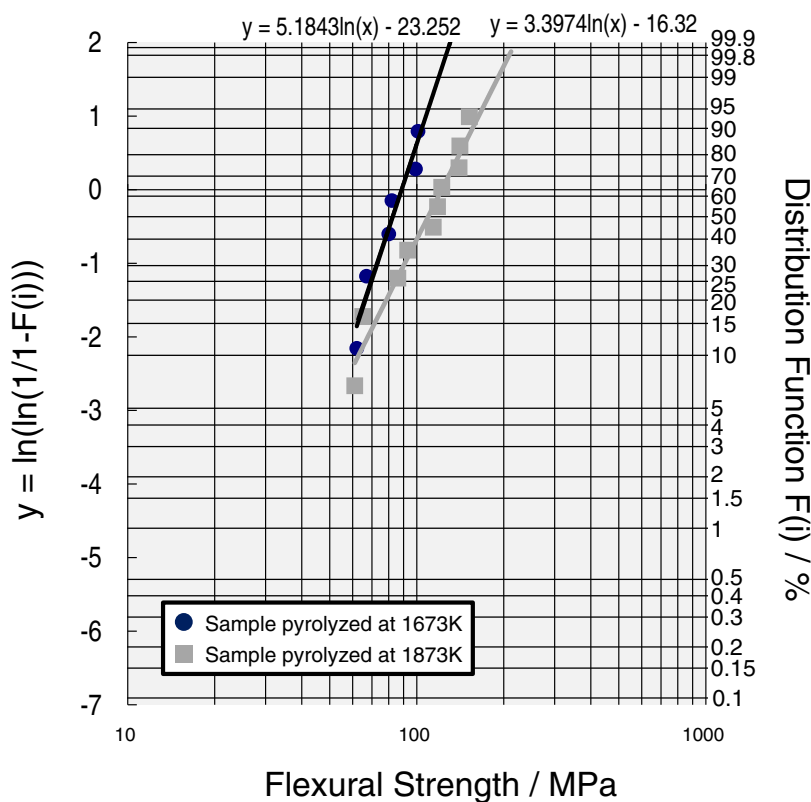

Fig. 6. (Color online) Weibull distribution of the 4 point bending tests of the samples.

These plots were calculated using the median rank method, which is shown by Eq. (1) and adopted for calculating the failure probability,

$$
F(i)=100 \frac{i-0.3}{N+0.4}
$$

where $N$ denotes the number of sample and $F(i)$ denotes the distribution function of the sample with the $i$ th weakest strength $(1<i<N)$. These $F(i)$ were substituted in Eq. (2).

$$
Y=\ln \ln \frac{1}{1-F(i)}
$$

The calculated $Y$ values are plotted on a logarithmic scale on the $y$ axis, and the flexural strength of the samples is plotted on the $x$ axis. The log approximation is also shown in the graph and the slope is the Weibull modulus. From Fig. 6, the Weibull modulus of the sample pyrolyzed at $1673 \mathrm{~K}$ was 5.18 and that of the sample pyrolyzed at $1873 \mathrm{~K}$ was 3.40 . This shows that the unevenness of the tensile strength in the same sample increases as the heating temperature increases.

\section{Conclusions}

In this investigation, we examined the possibility that PCS can be used as the binder in the joining of alumina. Any cracks on the surface of alumina were filled with PCS and there was no crevice between PCS and alumina after pyrolysis. At $1873 \mathrm{~K}$, PCS transformed to cristobalite and reacted with alumina to form mullite. The thickness of the joining area, which consisted of cristobalite and mullite, was about $5 \mu \mathrm{m}$. The average of the tensile strength was $109 \mathrm{MPa}$ and the maximum was $152 \mathrm{MPa}$. It is considered that the PCS decomposition and reaction with alumina increased the tensile strength and the thickness. As for pyrolysis at $1673 \mathrm{~K}$, when compared with the sample pyrolyzed $1873 \mathrm{~K}$, the tensile strength was lower because the diffusion of components due to PCS decomposition and alumina was not sufficient, however the unevenness of the tensile strength decreased.

Acknowledgment This research was supported by METI and NEDO, Japan, as part of the Project for the Development of Innovative Ceramics Manufacturing Technologies for Energy Saving.

\section{References}

1) K. Okamura and T. Seguchi, J. Inorg. Organomet. Polym., 2, 171-179 (1992).

2) H. Ichikawa, J. Ceram. Soc. Japan, 114, 455-460 (2006).

3) T. Iseki, K. Yamashita and H. Suzuki, J. Am. Ceram. Soc., 64, C13-C14 (1981).

4) R. E. Loehman, Key Eng. Mater., 161-163, 657-662 (1999).

5) X. Yuan, S. Chen, X. Zhang and T. Jin, Ceram. Int., 35, 32413245 (2009).

6) N. Kondo, H. Hyuga, H. Kita and K. Hirao, J. Ceram. Soc. Japan, 118, 959-962 (2010).

7) M. Nicolas, J. Mater. Sci., 3, 571-576 (1968).

8) H. Takashio, J. Ceram. Soc. Japan, 80, 163-174 (1972).

9) P. Colombo, G. Mera, R. Riedel and G. D. Sorarù, J. Am. Ceram. Soc., 93, 1805-1837 (2010).

10) S. Yajima, Y. Hasegawa, K. Okamura and I. Matsuzawa, Nature, 273, 525-527 (1978).

11) P. Martineau, R. Pailler, M. Lahaye and R. Naslain, J. Mater Sci., 19, 2749-2770 (1984).

12) P. Colombo, V. Sglavo, E. Pippel and J. Woltersdorf, J. Mater. Sci., 33, 2405-2412 (1998).

13) P. Colombo, B. Riccardi, A. Donato and G. Scarinci, J. Nucl. Mater., 278, 127-135 (2000).

14) A. Dong, Y. Katoh and A. Kohyama, J. Am. Ceram. Soc., 86, 26-32 (2003)

15) K. Kita, M. Narisawa, H. Mabuchi and M. Itoh, Key Eng. Mater., 352, 69-72 (2007). 